\title{
Igniting the Innovation's Competencies at Engineering Schools: IoT to the Cloud Labs Network in Mexico
}

\author{
José Ramón Morales-Avalos ${ }^{1, *} \&$ Yolanda Heredia-Escorza ${ }^{1}$ \\ ${ }^{1}$ Escuela de Humanidades y Educación, Instituto Tecnológico de Estudios Superiores de Monterrey, México \\ *Correspondence: Alejandro Dumas 142. Jardines Vallarta. CP. 45027. Zapopan, Jalisco. México. Tel: \\ 52-133-3955-1596. E-mail: jramonmorales@hotmail.com
}

Received: February 1, 2018

Accepted: March 14, 2018 Online Published: April 24, 2018

doi:10.5430/wje.v8n2p159

URL: https://doi.org/10.5430/wje.v8n2p159

\begin{abstract}
Learning and innovation's skills are increasingly recognized as key factors separating students who are prepared for more complex environments of life and work in the twenty-first century, and those who are not. The relationship between the industry and the academia is undoubtedly in Mexico and several countries nowadays a very important social and institutional phenomenon. Academy and Industry have always been cooperating in a win-win manner. Over time, this relationship has evolved in many mechanisms where learning skills developed strongly, but at present, innovation skills are taking more relevance. Efforts like an "IoT to the Cloud Innovation Labs Network" implemented by the Intel ${ }^{\circledR}$ Guadalajara Design Center in Mexico are contributing to foster the innovation's competencies and skills from students and have been having a profound impact at the local ecosystem at each one of the states where these labs are established. As part of the results, this labs network has been bringing more than 200 innovative projects, in different areas like smart agriculture, Internet of Things, automation, wearables, smart hearth, and robots, among others. Additionally, more than 3200 people (students, teachers, individuals from the industry and government) have been receiving some training coming from this labs network. All the courses and workshops have been deployed in a train the trainers' model, bringing a strong, scalable possibility and impact, to the local ecosystems and each one of the states.
\end{abstract}

Keywords: innovation, IoT, cloud, intel, Mexico, academia, competencies, internet of things

\section{Introduction}

\subsection{Background}

Knowledge is one of the key factors of our present society, a society that is the result of enormous technological transformations happened since the end of the seventies of the last century. This society called, not without controversy, "Knowledge Society" is subject to constant changes and challenges, due to the speed of technological advances. It refers to societies that are well educated, and therefore, dependent on the knowledge of its citizens to drive the innovation, entrepreneurship, and dynamism of economy of that society (OAS, 2017). It is a society in constant change, a society that evolves at great speed and that demands to the individuals a process of continuous learning, not only for their professional performance, including the one necessary for the full development of their daily life. Individuals are forced to adapt changing situations in all areas of human's performance and to adopt new knowledge and skills to cope with such changes, which are needed to compete and succeed in the face of economic and political changes in the modern world.

Unfortunately, poverty is no longer measured solely in economic or social terms. Now the world is also divided between those who dominate the new information and communication technologies (ICT) and those who do not. The enormous and growing inequality among nations or even between poor and rich regions about access to information and communication technologies (computers, mobile telephony, and Internet, among other devices), is what we know as the digital divide (Intel, 2015).

Based on this need, the education of children and young people continues to be one of the most important aspects of families and governments in all countries, but especially in Mexico. Nowadays, it is understood that, in a knowledge-based economy, a highly-educated labor force with a solid infrastructure of technology, education could be 
a way out to economic and social progress in any country. For reasons such as this, governments in many countries have incorporated into their political and economic agenda the integration of different learning frameworks. Even, they have been testing different and varied technologies, including information and communication technologies (ICT) among others, in schools, with the aim to develop a unified vision, goals, and strategy to enhance student learning.

For young people to succeed in the globalized and today's competitive world in which we live, traditional skills and competencies that for many years were taken as the foundation for education, such as writing, reading, and arithmetic, will continue to be critical skills. However, by themselves, they will not be enough. Different institutions and organizations in many parts of the world have been analyzing this problem, where learners need educational experiences in school and beyond, to build knowledge and skills for success in a digitally and globally interconnected world. Today's life and work environments require far more than thinking skills and content knowledge. The ability to navigate the complex life and work environments in the globally competitive information age requires students to pay rigorous attention to developing adequate life and career skills (Partnership for 21st Century Skills, 2017). In our century, competences like creativity, innovation, and entrepreneurship constitute a very important point of interest for the industry and society. Experts in this field, based on global trends, highlight these competencies as the relevant process to guide the talent development demanded by society as a whole, to find solutions to the limitations, deficiencies and structural problems that exist in a world uncertain and constantly changing (Hernández, Alvarado \& Luna, 2015).

In the same way, we must take into consideration, that in recent years, there have been many events in the area of technology that have had a significant impact on human life, causing unprecedented changes that have also been reflected in the social and economic aspects of all countries. These technological changes have produced a series of global environmental forces or movements, generating innovations, technological trends or megatrends that look promising. Several consulting firms have been carrying out different analyses to discern which will truly become a viable and impactful proposal or just the hype. As an example, the consulting firm Gartner, which created the concept of Hype Cycles, which is a graphic representation of the maturity and adoption of technologies and applications, and how they are potentially relevant to solving real problems and exploiting new opportunities (Gartner, 2016).

Here the relevance that the academia has in Mexico. The academia plays a critical role in the training of professionals so that they can meet the challenges of the 21 st century. It's not only to find out how these competencies will be implemented and developed but as well understand how all these megatrends or Hype Cycles would impact the current curricula so that the students become the future professionals that society and the industry would require.

The collaboration between industry and academy or, simply, the industry-university relationship is undoubtedly a very important social and institutional phenomenon in Mexico nowadays, but also a very complex one. At the conceptual level, it touches a large number of core national development's aspects such as country competitiveness, talent development, human resources' quality, culture, economy, and innovation, just to mention a few. At a concrete level, it is a phenomenon difficult to pin down, due to the wide variety of universities and industries, where modalities or real forms of interaction would depend on terms and conditions mutually agreed. Although industry-academia's relations are not a new phenomenon, it is clear that in the last decades they have become more prominent, to the extent that their promotion has become a key component of the innovation policies implemented by several governments around the world. The interest in promoting this kind of collaboration has found support and impetus in the emergence of diverse approaches that emphasize the importance of interactions between scientific and productive agents, not only for business' innovation but also for the development and social validation of University's research (Montiel, 2014).

\subsection{Impact of Industry-University Collaboration on Innovation}

Innovation, as well as the use of knowledge, play a fundamental role in the new economic scenario in which we find ourselves, both factors being very interrelated. Productivity and growth are largely based on technical progress and accumulation of knowledge. These new changes in the conception of the economy require new indicators to assess the economic situation over time and space, with the complexity of measuring a variable with as much current weight as knowledge. As indicated in the last OCDE report (OCDE, 2016), it is clear that developed countries are moving very fast towards the new knowledge society. In emerging countries, as is the case in Mexico, sometimes this transition towards a knowledge society is more gradual.

Nowadays, there is a strong growth of investments in equipment, fixed assets (mainly computer's hardware) and intangible resources (education, $\mathrm{R} \& \mathrm{D}$, software, etc.). Additionally, an increase in talent development's efforts and a rapid growth of knowledge-based industries (High technology industries and specialized personnel, both those that generate technology and those that use it). It is also worth noting the rapid diffusion of the new information technologies and especially of the Internet, both being clear indicators of the development of the knowledge society 
and the new knowledge economies (Hernández, Alvarado \& Luna, 2015). The word Innovation appears continuously as a synonym for progress, technological development, job creation, and improvement of living conditions. Innovation is happening everywhere. From economic and industry fields (e.g., technological innovations in companies) to social areas (health, leisure, working conditions, transport, etc.). It seems clear that in today's world of global and increasingly competitive markets, with the need for job creation, the incorporation of a culture of innovation in all social and economic sectors, it is seen as a necessity.

In Mexico, different initiatives at the federal level and in particular at the state level have been implemented as a way of facilitating local economies to adapt to a constantly changing global environment, reconverting and innovating in any field, becoming a key factor to development. In the increasingly bitter competition for attracting investments and talents, those who do not keep pace with technological, organizational and marketing changes will be irrevocably relegated. That is why, in several states of the Mexican Republic, a greater amount of resources are directed towards the promotion of innovation and effective collaboration that articulates all the efforts of all the key agents: companies, universities and research centers, governments and society (Montiel, 2014).

Innovation is the key idea that is currently shaping business life, helping leaders and entrepreneurs conceive options never imagined before. Innovation enables potential ideas to be viewed through different lenses, not only from a cost-benefit perspective but also as a means of improving the ability to enter new markets faster and deeper. A culture of innovation is critical to success and may require openness to change in procedural and problem-solving approaches. Innovation environments require a different set of skills, competencies, and attitudes for all involved: collaboration, experimentation, uncertainty, recognition of failure and open-mindedness are essential (Montiel, 2014).

Innovation is produced through new forms of collaboration and association. An example of this collaboration is the Innovation's labs. An innovation's lab could be a space and a set of protocols to involve individuals, technologists, universities, civil society, the public and private sector in solving problems; it is a physical space that allows collaboration between those actors (UNICEF, 2012). Some problems can only be solved when the direct ones develop solutions through collaboration and innovation. Collaborative work, in an educational context, invites students to build together, for which it requires combining efforts, talents, and skills through a series of transactions that allow them to achieve the goals established by consensus (Pérez, 2007).

In an innovation laboratory, private sector's partners, non-governmental organizations, academia, government, civil society and youth can co-create solutions around specific local problems and address these solutions on a global scale.

\subsection{IoT to the Cloud Labs Network in Mexico}

In recent years, the exponential growth of knowledge and technology is forcing many companies to renew faster than in previous years, taking new needs or delivering new products or services. However, on several occasions, the growth in areas of opportunity does not go hand in hand, with the development of talent that is necessary by the universities for the industry.

Based on this problem, Intel ${ }^{\circledR}$ Corporation, one of the greatest technology companies worldwide and his Guadalajara Design Center (Intel ${ }^{\mathbb{R}}$ GDC), implemented an initiative in the middle of 2016 in Mexico, to develop more Mexican's talent and promote universities' innovation efforts. Intel ${ }^{\circledR}$ GDC is the largest engineering center in the Latin America region for Intel ${ }^{\circledR}$, focused on delivering Intel's state of the art technology in different areas. Intel ${ }^{\circledR}$ GDC was started in October 2000 and has grown to date to more than 1,800 people (Intel, 2017).

In May 2016, Intel ${ }^{\circledR}$ GDC visited several states in Mexico driving research to analyze in the universities three factors:

a) The quality of the talent that the universities were producing in the engineering school

b) The level of innovation that the projects of the students were having at this area

c) The collaboration with the local ecosystem - mainly the support that the universities give to the small and medium companies and the overall industry.

In some cases, several deficiencies were detected. A great challenge not only for Intel ${ }^{\circledR}$ but for any other company interested in helping the academia and society is to be effective through strategies that can scale and have a high local impact.

Based on this problem, Intel ${ }^{\circledR}$ GDC implemented the strategy of creating a network of laboratories in Mexico with these major objectives:

- Foster Mexican students' talent development

- Ignite innovation competencies at the academia 
- Increase the collaboration among the universities and the entire ecosystem

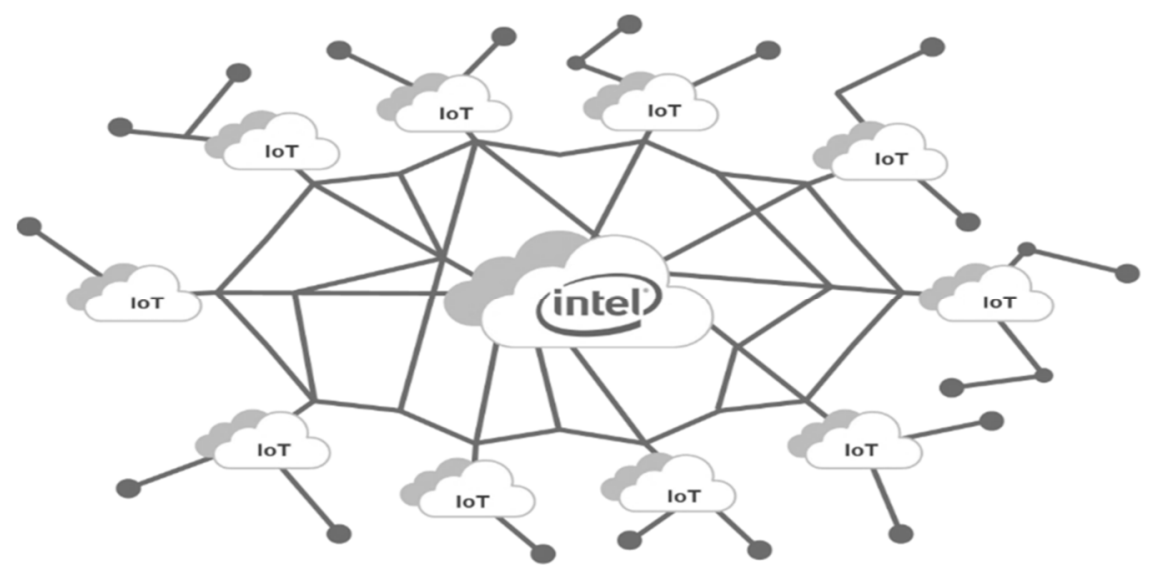

Figure 1. IoT to the Cloud Labs' Network

For this purpose, in an initial phase, Intel ${ }^{\circledR}$ GDC selected ten states in Mexico to implement these labs network, which included both private and public universities.

Table 1. Universities and States of Mexico Selected in May 2016

\begin{tabular}{lcc}
\hline State & City & University \\
\hline Jalisco & Guadalajara & $\mathrm{U} 1$ \\
Baja California & Mexicali & $\mathrm{U} 2$ \\
Sonora & Cd. Obregón & $\mathrm{U} 3$ \\
Chihuahua & Chihuahua & $\mathrm{U} 4$ \\
Nuevo León & Monterrey & $\mathrm{U} 5$ \\
Querétaro & Querétaro & $\mathrm{U} 6$ \\
Zacatecas & Zacatecas & $\mathrm{U} 7$ \\
Yucatán & Mérida & $\mathrm{U} 8$ \\
Hidalgo & Pachuca & $\mathrm{U} 9$ \\
Puebla & Puebla & $\mathrm{U} 10$ \\
\hline
\end{tabular}

Description. List of states and cities where an IoT to the Cloud Lab was established by Intel® GDC.

Source: Adapted by the author (2017).

Each university had to sign a legal contract in which 13 points are included, being especially significant the following ones:

- The commitment to have on an annual basis ten highly innovative projects that have an impact on their local ecosystem.

- Collaborate with other Universities and institutions, hosting 2 to 3 annual events to replicate the training received by Intel® GDC.

- Scale and replicate the innovation lab received, in the least another university or research center.

- $\quad$ Each laboratory, based on its geographic location, local ecosystem, and conditions, should specialize and lead an area such as industry 4.0, education, health, agriculture, automotive, aerospace, robotics, among others.

It's in important to mention that all the intellectual property and the ownership of the projects will remain at the university. 
Based on the megatrends that have been having a major impact in Mexico in the area of technology and the feedback from several studies -including the methodology of Gartner Hype Cycle (Gartner, 2016), it was defined that some of the biggest growth areas would be on the Internet of the Things and several Cloud and Datacenter's technologies.

Centered on this information, validated by the industry and in some cases by the government - e.g., Ministry of Innovation of the State of Jalisco, the strategy of the implementation of these innovation labs was established in 3 phases.

- The first phase consisted in the donation of state-of-the-art IoT technology based on Intel ${ }^{\circledR}$ architecture. In the same way, different kits were included with sensors and Intel ${ }^{\circledR}$ Real Sense cameras. The Intel ${ }^{\circledR}$ Software Development Kit was included, and in some cases, open source software and applications were donated.

- The second phase was the training phase face. Different pieces of training and workshops were offered for the teaching staff of these universities, in a scheme of "train the trainers" based on an inverted classroom scheme. After this training, on a monthly basis have been offering training in other areas, having a high priority in 2017 all the technologies of Cloud and Datacenter.

- Finally, in collaboration with the University, all the marketing elements were introduced to dress the laboratory and the area assigned to this effort with the Intel ${ }^{\circledR}$ brand.

The final step was defined to formally announce the lab to the ecosystem, in collaboration with the local government, industry, society and other academic institutions.

Table 2. General Criteria for Innovative Projects' Evaluation

Criteria

1. Technological level

2. Project' singularity

3. Value-added

4. Economics' factors

5. Ecosystem's impact

6. Documentation's quality

\section{Definition}

Level 1. Standard (good solution by methods known in the field is very elementary, not new, it is a contribution, not a real invention).

Level 2. Improvement (development of an existing system, usually with some degree of progress and complication.) The used methods within the same industry or some related one. Level 3. Invention or innovation within the paradigm, trade matter (fundamental or essential improvements of existing systems using methods from other fields).

Level 4. Inventions outside the paradigm of creating a new generation of existing systems changing the behavior principle of the primary function: "Non-technological, but scientific solutions."

Level 5. Discovery, pioneers in the invention of a new system. Usually, based on a great discovery, like a new science, it's the kind of discovery

How many similar jobs exist?

It is the result of technological searches (based on patents, similar works on the internet) and the degree of being ideal (Highly favorable qualities that can be obtained)

In what degree of relevance resolves the need or solves the problem of the market or the community. How to promote the improvement of productive activities, the competitive technological advantage that it generates. Effects on productivity.

Do you generate jobs? Does it reduce operating costs? Are other benefits obtained?

The contribution to the company, community or society, the ecological impact, and improvements in the quality of life.

Quality in the presentation of information, integration (content structure, logical sequence of ideas) Writing and spelling. The use of relevant references (technological search, bibliography, the justification for the use of graphics information supports an important support annexes).

Description. General evaluation's criteria for innovative projects recognized by Premio Tecnos

Source: Premio Tecnos (2007). 


\section{Method}

\subsection{Objective}

The objective of this document is to describe the innovation competencies' development in engineering students in technology's careers. This analysis is based on projects generated by innovation labs incorporated at the university in collaboration with the industry, in six states of the republic, describing some of the innovative projects generated by the IoT to the Cloud labs network in Mexico.

\subsection{Type of Research}

The design of the present study falls into the category of a descriptive study. Frequently, the researcher's goal is to describe phenomena, situations, contexts, and events. The descriptive studies seek to specify the properties, characteristics, and profiles of people, groups, communities, processes, objects or any other phenomenon that is subjected to analysis (Hernández, Fernández \& Baptista, 2006). In this case, the analysis was done on academia's projects selected randomly from a database provided by Intel ${ }^{\circledR}$. To standardize the evaluation criteria of the projects that were taken into consideration as a record of the innovation carried out by the institution. Different evaluations' frameworks were analyzed, being one of the most relevant to this research, the General Criteria of Innovative Product Evaluation (Premio Tecnos, 2007), which includes the following criteria described in table 2.

\subsection{Sociodemographic Context}

The research was carried out in eight states of the Mexican Republic, at universities and technological institutes, both public and private, in engineering areas. The engineering areas selected for this investigation were: Innovation, Electronics, Computing, Mechatronics, Mechanics, Cybernetics, and finally, Industrial. It is important to mention that, depending on the institution, the name of the career might change slightly, so it was given the option of choosing other similar careers to the previous list.

\section{Results}

Social, technological and economic transformations, such as globalization, vertiginous technological changes (which are increasingly more pronounced), and changes in communication and information systems, have a decisive impact on the way in which develops the link between government, university, and industry. The importance of the exchange of knowledge and therefore of relations stands out, encouraging an environment that is part of a country development generating new knowledge (Castillo, 2010). For Mexico, this is one of the top priorities. Efforts such as the IoT to the Cloud labs network implemented by Intel ${ }^{\circledR}$ GDC have been providing very promising results.

Table 3. Example of Projects from the IoT to the Cloud labs network in Mexico

\begin{tabular}{ccl}
\hline University & Project & Example of projects \\
\hline U2 & P1 & -Sircuit, the fancy way to test your circuits \\
& P2 & - Bionic Prostheses and Physical Rehabilitation Equipment \\
U3 & P3 & -Virtual Fitness Coach \\
& P4 & -cLoud Stethoscope \\
U4 & P5 & -A Ciphered Database for Medical Records Based on an IoT Wearable Security Token \\
& P6 & - Water Quality Monitoring in Remote Shrimp Farms \\
U5 & P7 & - Real-time data collection of the state of an automobile in everyday use \\
& P8 & - Collection of data on the environmental and corporal conditions of cattle \\
U7 & P9 & - Smart City Phase 1. Automation of public transport \\
& P10 & - Platform for study, diagnosis, follow-up and early prevention of childhood cancer. \\
U10 & P11 & -Environmental monitoring platform, from an Internet perspective of things. \\
& P12 & -A monitoring system for the location of a fleet of vehicles via the internet
\end{tabular}

Description. List of some of the projects generated by the IoT to the Cloud Labs Network in 2017

Source: Adapted by the author (2018)

Based on the information provided by the Intel ${ }^{\circledR}$ GDC, at the end of 2016, eight from ten laboratories were inaugurated in different universities, operating at 100\%. Through this effort, more than 3200 people have been trained, including teachers, students, small and medium companies. This labs network has been bringing more than 200 projects in different areas, such as industry 4.0, IoT, robotics, smart agriculture, health, among others, where the support to the 
small and medium enterprises and the local ecosystem in each of the states has been a priority. A great example of how this labs network is already scaling the program is COZYT, a laboratory part of this network based in Zacatecas. They had the opportunity to open two subnetworks in other state's universities as part of this initiative.

Specifically for this research, an analysis was done on academia's projects selected randomly from a database provided by Intel ${ }^{\circledR}$, those created on the 2017 period. A group of three evaluators reviewed each one of the projects and gave their evaluation independently. Evaluators came from academia, industry (Intel ${ }^{\circledR}$ ) and an expert who knows the prize. The final score was consolidated by the given average. Depending on the final objective of the competition, the table with the evaluation showing the different criteria, provide an easy way to identify the possible winners.

Table 4. Projects' Evaluation Based on Premio Tecnos (2007) Criteria

\begin{tabular}{ccccccc}
\hline Project & C1 & C2 & C3 & C4 & C5 & C6 \\
\hline P1 & Level 2 & 2 & 2 & 1 & 2 & 3 \\
P2 & Level 3 & 3 & 4 & 2 & 4 & 3 \\
P3 & Level 1 & 2 & 2 & 2 & 3 & 2 \\
P4 & Level 2 & 2 & 2 & 1 & 2 & 2 \\
P5 & Level 3 & 2 & 3 & 1 & 4 & 2 \\
P6 & Level 5 & 5 & 5 & 2 & 5 & 3 \\
P7 & Level 2 & 3 & 3 & 2 & 3 & 3 \\
P8 & Level 2 & 4 & 4 & 2 & 4 & 3 \\
P9 & Level 3 & 3 & 4 & 2 & 4 & 3 \\
P10 & Level 4 & 4 & 4 & 1 & 4 & 3 \\
P11 & Level 3 & 3 & 2 & 1 & 3 & 3 \\
P12 & Level 2 & 2 & 2 & 1 & 3 & 2 \\
\hline
\end{tabular}

Description. Evaluation of the projects generated by the IoT to the Cloud Labs Network in 2017 using the Premio Tecnos 2007 criteria. C1-Technological level, C2- Project' singularity, C3- Value added, C4- Economics' factors, C5Ecosystem's impact, and C6- Documentation's quality.

Source: Adapted by the author (2018)

Several projects have been bringing a very important impact not only on the industry but the local states. From the projects described in table 3, a good example that reflects the local innovation and the impact that these labs are having is the $\mathrm{P} 6$ project:

$>$ Shrimp farming in Mexico has been an activity that has gone through several sanitary events, having a devastating impact on the local economy over the past years. In 2013, an epidemy, affected almost the $80 \%$ of the shrimps' production in Mexico, affecting more than 100 thousand tons that year. By having the opportunity to implement IoT technologies, it would allow bringing a water's quality monitoring system, where the farmers can take preventive actions in real time.

Nowadays, is quite common to see that the academy every year launches different initiatives and contests to generate innovative ideas. Unfortunately, there are two major tendencies at these contests: the first one is to come with several innovative ideas without articulating a clear problem to solve. The second refers to the point where it's very rare to see widespread replication or scale of these projects once the contest or event is over (Howard, 2011). Notwithstanding the limitations on the contest, the results obtained reflect the development of the competence of innovation in the students, the level of maturity of the ecosystem, in which the efforts of the academic, the industry, and the government are combined.

\section{Discussion}

The academia, in general, seeks to be the center of thought, debate, culture, and innovation; it is important to emphasize that it is convinced of the need to remain in tune with the surrounding reality and with the new paradigms of higher education (González \& Wagenaar, 2004). Chang (2008) believes that, by consistently emphasizing both the creative process and the thinking strategies outlined in the collaboration models, individuals and companies could become inventive and innovative long before they decide to use another method. Therefore, creativity and innovation are not inherent traits but can be taught and developed using different process frameworks and appropriate pedagogies (Waychal P., Mohanty, R. \& Verma, A., 2011). In today's world, of global markets and increase of competitiveness, 
the need for job creation, innovation is posed as a need (Gonzalez, 2012).

The IoT to the Cloud labs network opens the doors to different areas of research, considering that several universities have understood that it is crucial to analyze, understand and incorporate new practices and knowledge focused on a knowledge society, where technology is advancing in an accelerated way, new megatrends and hype cycles are emerging. Including the fact that collaboration with industry allows them to incorporate strategies that foster innovation competencies in students, specifically in the area of technology in Mexico, one of the most demanded in the country.

A future critical area to be researched is understanding how students' innovation competencies are developed in universities in the area of technology and the possible impact that state-of-the-art technology is having on these innovation cycles at engineering schools. Every day new megatrends are born in the technological field - some are critical and fundamental for the development of areas such as automation, robotics, smart cars, advanced manufacturing, industry 4.0, smart cities just to mention some. Universities should be prepared to increase the technological awareness and knowledge of their students, in these areas.

Based on society and the needs of the industry, some programs of cross-collaboration programs have been implemented between academia and industry, with the aim of developing new talent and increasing technological talent in these new megatrends. However, some specific efforts such as the creation of a network of innovation laboratories focused on these areas in Mexico, led by one of the top technological companies in conjunction with some universities, stand out, as a unique initiative of the collaboration between the industry and the academia.

\section{References}

Castillo, H. G. C. (2010). El modelo de la triple hélice como un medio para la vinculación entre la universidad y empresa. Revista Nacional de Administración, 1(1), 85-94.

Chang. (2008). Engaging the creative minds-the Engage Models. International Journal of Innovation and Technology Management, 5(1), 149-65. https://doi.org/10.1142/S0219877008001254

Gartner. (2016). Gartner's 2016 Hype Cycle for Emerging Technologies Identifies Three Key Trends That Organizations Must Track to Gain Competitive Advantage. Gartner, Inc. Retrieved from: http://www.gartner.com/newsroom/id/3412017

González, J., \& Wagenaar, R. (2006). Tuning Educational Structures en Europa. Informe Final. Proyecto Piloto, Fase 2, de la Universidad de Deusto y Groningen). Bilbao: Universidad de Deusto, 423 pp.

Hernández Arteaga, I., Alvarado Pérez, J. C., \& Luna, S. M. (2015). Creatividad e innovación: competencias genéricas o transversales en la formación profesional. Revista Virtual Universidad Católica del Norte, 44, 135-151.

Hernández Sampieri, R., Fernández-Collado, C., \& Baptista P. (2006). Metodología de la investigación (4 ${ }^{\text {th }}$ ed.). Distrito Federal, México: McGraw-Hill.

Howard, A. (2011). Everyone jumped on the app contest bandwagon. Now what?. Retrieved from: http://radar.oreilly.com/2011/08/app-contests-sustainabilityusability.html

Intel. (2015). Bridging the digital Divide-Nigeria. Intel Corporation. Retrieved from: http://www.intel.com/content/www/us/en/education-solutions/bridging-digital-divide-nigeria-paper

Intel. (2017). Mexico locations. Retrieved http://www.intel.com/content/www/us/en/jobs/locations/mexico/sites/guadalajara.html

Montiel, I. (2014). Índice de innovación de las entidades federativas 2014. México Innovación y Diseño. Centro de Inteligencia de México Innovación y Diseño (MIND).

OAS. (2017). Sociedad del conocimiento. Organization of the American States. OEA. 2017. Retrieved from http://www.oas.org/es/temas/sociedad_conocimiento.asp

OCDE. (2016). OECD Science, Technology and Industry Scoreboard. Organization for Economic Co-operation and Development. Retrieved from: http://www.oecd.org/sti/scoreboard.htm

Partnership for 21st Century Skills (2017). Framework for 21st Century Learning. P21. 1 Massachusetts Avenue NW, Suite 700 Washington, DC 20001. Retrieved from http://www.p21.org/our-work/p21-framework 
Pérez, M. (2007). EL TRABAJO COLABORATIVO EN EL AULA UNIVERSITARIA. Universidad Pedagógica Experimental. Laurus, vol. 14, núm. 28, septiembre-noviembre, 2008, pp. 158-180. Venezuela. Retrieved from: http://www.redalyc.org/pdf/761/76111716009.pdf

Premio Tecnos. (2007). Internacional Competitiveness in Technological Development. Secretaría de Desarrollo Económico. Goverment of Nuevo León, México.

UNICEF (2012). Laboratorios de innovación. Una guía práctica. Unicef. Retrieved from https://www.unicef.org/videoaudio/PDFs/laboratorios-de-innovacic3b3n-una-guc3ada-pre3a1ctica1.pdf

Waychal P., Mohanty, R., \& Verma, A. (2011). Determinants of innovation as a competence: An empirical study. International Journal of Business Innovation and Research, 5, 192-211. https://doi.org/10.1504/IJBIR.2011.038781 